\title{
El último fin y el quehacer teológico de acuerdo con santo Tomás: entre el intelectualismo y el voluntarismo $^{1}$
}

\section{The ultimate goal and the theological pursuit according to Saint Thomas: between intellectualism and voluntarism}

Oscar Edmundo Yangali Núñez ${ }^{2}$

Universidad Femenina del Sagrado Corazón

\section{Resumen}

En este trabajo, desarrollo la importancia de la reflexión de Tomás de Aquino acerca de la relación entre el entendimiento y la voluntad con respecto al quehacer teológico. Examino primero el llamado intelectualismo de santo Tomás. Luego, procedo a discutir y resolver en qué consiste la concepción tomista de esencia. Y, finalmente, presento el aporte que representa el amor de caridad en el quehacer teológico. Concluyo que el pensamiento y la actualidad de santo Tomás para la

1 Este trabajo se basa en una ponencia presentada en el Conversatorio sobre la Actualidad de Santo Tomás de Aquino, realizada en el Instituto Riva Agüero el 28 de setiembre del 2017.

2 Docente de la Universidad Femenina del Sagrado Corazón y del Seminario Mayor Diocesano San José de Lurín. Código ORCID 0000-0002-0817-0165 Contacto: oscar.yangali87@gmail.com, oscaryangalin@unife.edu.pe 
teología reside en una unidad esencial, una base metafísica y antropológica, que establece una relación entre la comprensión de la doctrina y la vivencia del evangelio fundamentada en el amor de caridad.

Palabras clave: forma, materia, esencia, intelectualismo, voluntarismo, teología, caridad

\section{Abstract}

In this work, I develop the importance of Thomas Aquinas' reflection on the relationship between understanding and will with respect to the theological work. I examine first the so-called intellectualism of St. Thomas. Then, I proceed to discuss and resolve what the Thomistic conception of essence consists of. And finally, I present the contribution that the love of charity represents in the theological pursuit. I conclude that the thought and timeliness of St. Thomas for theology resides in an essential unity, a metaphysical and anthropological basis, which establishes a relationship between the understanding of the doctrine and the experience of the Gospel based on the love of charity.

Key words: form, matter, essence, understanding, intellectualism, voluntarism, theology, charity

\section{Introducción}

Sin duda alguna, el último fin de toda criatura humana consiste, para un pensador cristiano de la Edad Media, en la consecución de la bienaventuranza eterna. No es, pues, la excepción el caso de santo Tomás de Aquino, para quien la bienaventuranza se define esencialmente como la contempla- 
ción de Dios, el sumo Bien. Hacia este último fin nos debería conducir la teología, tanto mediante su aparato conceptual cuanto por medio de su meditación y aplicación. Así, el quehacer teológico está estrechamente vinculado a la búsqueda de Dios como fin trascendente y su materialización en la vida humana. Esta es la manera como entendemos la instauración del Reino de los Cielos en la tierra.

Sin embargo, las posturas en el periodo medieval acerca de cuál es la naturaleza de la bienaventuranza del ser humano difieren en sus fundamentos. Las propuestas de los distintos pensadores para definir cuál es la esencia de la bienaventuranza tienden a favorecer el rol del intelecto o de la voluntad dependiendo del concepto que tienen de lo que es la esencia y la naturaleza humana. He ahí la importancia del tema que se va a tratar, porque la esencia de la bienaventuranza se encontraría preeminentemente en una de estas dos facultades. De estas dos posibles concepciones acerca de la esencia de la bienaventuranza, hay posturas "intelectualistas" y "voluntaristas".

3 La postura voluntarista sostiene que lo más importante para ser bienaventurado consiste en vivir la voluntad conforme a la voluntad de Dios, a saber, en el amor de la voluntad poniendo énfasis en la bienaventuranza y no en lo que la posibilita. Muchos historiadores de la filosofía medieval han colocado a Santo Tomás como opositor a una concepción "voluntarista» y dentro de una posición «intelectualista». No es el propósito de esta exposición examinar la postura de Santo Tomás respecto de este tipo de posiciones, sino exponerla de tal manera que no se le interprete de un modo estrictamente intelectual. Ejemplos de posiciones voluntaristas fueron las de Juan Duns Escoto (Gilson, 2007, pp. 587-595), y la de Guillermo de Ockham (Copleston, 2004, pp. 108-114). 


\section{Santo Tomás de Aquino y su supuesta posición «inte- lectualista»}

La postura adoptada por santo Tomás en torno al tema de la bienaventuranza, a partir de lo sostenido en su teología, podría encajar aparentemente en una de estas dos opciones. Esta sería, la de la preeminencia esencial del intelecto sobre la voluntad, es decir, una defensa intelectualista acerca de la esencia de la bienaventuranza. En la Suma de Teología, santo Tomás nos dice:

"Como ya se señaló (q. 2 a. 6), para la bienaventuranza se requieren dos cosas: una, lo que es la esencia de la bienaventuranza, y la otra, lo que la acompaña como accidente propio, es decir, la delectación consiguiente. Digo, por tanto, que es imposible que la bienaventuranza consiste en un acto de la voluntad, en cuanto a lo que es esencialmente la bienaventuranza, pues se desprende claramente de lo antes dicho (a. 1 y 2; q. 2 a.1), que la bienaventuranza es la consecución del fin último. (...) Pero es claro que el deseo mismo del fin no es su consecución, sino un movimiento hacia el fin. Ahora bien, la delectación le llega a la voluntad precisamente porque el fin está presente y no al contrario, que algo se haga presente porque la voluntad se deleita en ello. Por tanto, es necesario que haya algo distinto del acto de la voluntad por lo que el fin se haga presente a quien lo desea" ([1265] 2009, p. 61).

192 La bienaventuranza es definida esencialmente como un acto del intelecto y no de la voluntad. Esto, debido a que la voluntad no puede moverse hacia un fin si este no se encuentra presente en nuestro conocimiento o visión. Por lo que es necesario que para alcanzar la bienaventuranza primero opere nuestra intelección y solamente así pueda nuestra voluntad deleitarse en Dios por medio de su amor. En otras palabras, 
nadie puede amar con su voluntad lo que no conoce previamente con su intelecto.

Esta parte de la Suma de Teología ha hecho que, por mucho tiempo, e incluso hoy para algunas lecturas no muy detalladas, se piense que santo Tomás adoptó una postura "intelectualista" sobre la esencia de la bienaventuranza, ya que de acuerdo con lo dicho sería patente que la esencia de la misma consistiría en un acto del intelecto mas no de la voluntad. Tales han sido, por ejemplo, los pareceres de Wulf (1945), para quien la dependencia de la voluntad respecto al intelecto, debido a que este le presenta a ella lo que se encuentra en la razón de bien, le hace considerar que en santo Tomás la teoría de la libertad sea una forma de intelectualismo (p. 148). Así mismo, Gilson (1985) enfatizaba que la felicidad se constituye, para santo Tomás, en la consecución de la verdad y el ejercicio de las ciencias especulativas (p. 501); sostenía también que el intelecto es donde radica la imagen de Dios en el hombre y así justifica esta postura intelectualista (2002, p. 43).

Ahora bien, ¿acaso este asunto teológico está finiquitado por estas palabras? ¿Es que santo Tomás sería, en efecto, un teólogo intelectualista? Es más, ¿por qué tendría esta postura repercusiones en la teología como quehacer? Para responder estas preguntas ha de considerarse no solamente lo dicho por santo Tomás en el pasaje citado, sino a la luz de sus concepciones metafísicas y éticas. Definitivamente, hay más por hurgar en su obra que nos permita cambiar o por lo menos matizar esta concepción denominada "intelectualista”. Además, las consecuencias de adoptar una postura intelectualista, al postular que nuestro intelecto es condición suficiente para alcanzar a Dios, podrían ser insuficientes para agotar la explicación de 
la esencia de la vida bienaventurada en un sentido cristiano. El reconocido historiador jesuita Frederick Copleston había intuido perfectamente que para santo Tomás el fin último del ser humano no se podía reducir a una postura meramente intelectualista, ya que el fin último no consiste en ser filósofo, como postulaba Aristóteles, sino en ser santo (pp. 386-387). En caso contrario, el quehacer teológico también podría verse afectado de manera negativa, pues se reduciría, por un lado, a una mera cuestión de incentivar en el entendimiento la aceptación de una doctrina y, por otro lado, de una simple conformidad de la voluntad ante los preceptos y normas derivados de la misma. Esta sería la consecuencia de haber aceptado la preeminencia de la condición de suficiencia de nuestro intelecto para encaminar a la voluntad. Por supuesto, esta no sería una conclusión necesaria a partir de lo enunciado por santo Tomás, pero no desarrollar esta concepción de manera matizada podría conducirnos, si no en la teoría al menos sí en la práctica, a un perjuicio nocivo del significado que tiene nuestra voluntad para llevar una vida bienaventurada. Siendo la vida bienaventurada la mejor condición posible para vivir el evangelio, sin duda, su simplificación acarrearía un perjuicio en el quehacer teológico. Por todo ello, para aprender a no opacar nuestro quehacer teológico es menester reconocer el mérito de la concepción tomista acerca de nuestro último fin resolviendo que es imposible la exclusión de la

194 voluntad a pesar de que, aparentemente, no forma parte de la esencia de la bienaventuranza.

\section{Refutación de la posición «intelectualista» de santo Tomás}

A fin de contrarrestar el intelectualismo que se podría atribuir a santo Tomás e incorporar la actuación inherente de la 
voluntad para la esencia de la bienaventuranza, me valgo de la siguiente cita:

"La rectitud de la voluntad se requiere para la bienaventuranza antecedente y concomitantemente. Antecedentemente, en efecto, porque la rectitud de la voluntad existe por el orden debido al fin último. Ahora bien, el fin se relaciona con lo que ordena a él, como la forma con la materia. Por eso, lo mismo que la materia no puede conseguir la forma si no está debidamente dispuesta para ella, nada puede conseguir el fin si no está ordenado a él debidamente (...).

Concomitantemente también, porque, como ya se dijo (q. 3 a. 8), la bienaventuranza última consiste en la visión de la esencia divina, que es la esencia misma de la bondad. Y así la voluntad del que ve la esencia de Dios necesariamente ama cuanto ama en orden a Dios; (...) Por consiguiente, es claro que no puede haber bienaventuranza sin voluntad recta” (Aquino, [1265] 2009, p. 73).

La esencia de la bienaventuranza no puede ser conseguida sin una voluntad recta, es decir, una voluntad ordenada en el amor de Dios, por lo que ordenar la voluntad se convierte en condición necesaria para alcanzar la visión de Dios. La consecución del fin último por parte de nuestra visión es proporcional a la rectitud de la voluntad como la forma lo es a la materia. De modo que el fin último no puede concretarse para el ser humano si es que no se tiene una voluntad debidamente dispuesta para permitir la bienaventuranza.

Es evidente que santo Tomás no termina su concepción acerca de la esencia de la bienaventuranza con sus primeras palabras, sino que le atribuye a la voluntad un rol de condición necesaria para conseguir nuestro último fin. Al ser la voluntad inseparable de la consecución de la bienaventuranza, hay que decir que el intelecto será condición necesaria mas no 
suficiente de la misma, por más que sea él quien vea la esencia divina.

Empero, ¿cómo conciliar ambos pasajes de la obra de santo Tomás? ¿Acaso nuestro autor se contradice? Afirmo rotundamente que no. Si notamos las palabras que emplea, nos daremos cuenta de que hay una concepción metafísica de por medio, la cual también tiene un correlato ético. Esta concepción metafísica tiene como base lo que santo Tomás entiende por esencia. En otras palabras, cuando santo Tomás define lo que es la esencia de la bienaventuranza lo hace en virtud de cómo entiende en general lo que es la esencia de algo. Motivo por el cual, en el primer pasaje seńala que la esencia de la misma consistirá en una operación del intelecto; no obstante, en el segundo pasaje pareciera que lo que nos quiere decir es que la voluntad también pertenecería a la esencia de la misma siempre y cuando tengamos en cuenta esta comparación de la contemplación intelectual y la rectitud de la voluntad en una relación con la forma y la materia.

Veamos cómo entiende santo Tomás en El ente y la esencia lo que es la esencia de las cosas compuestas de nuestro mundo natural:

"En las substancias compuestas son conocidas la forma y la materia, como en el hombre el alma y el cuerpo. Pero no puede afirmarse que la esencia se diga sólo de una de ellas. (...) En efecto, según todo lo dicho, es patente que la esencia es aquello que es significado por la definición de la cosa. La definición de las substancias naturales no sólo contienen [sic] la forma, sino también la materia, pues de otro modo no diferirían las definiciones naturales y las definiciones matemáticas" ([1256] 2011, p. 271). 
Para santo Tomás la esencia de algo consiste en su ser compuesto, a saber, tanto en su forma como en su materia. La esencia no se puede decir solamente de una de ellas, debido a que lo que define, por ejemplo, a un ser humano no es únicamente su forma humanidad, sino la materia que lo compone, ya que es un ser humano. Ciertamente, podemos abstraer algún concepto puramente formal del ser humano, pero ello no agotaría lo que compone a un ser humano concreto o cómo se da en la realidad. Por ello, de acuerdo con santo Tomás, lo que define esencial o naturalmente a un ser humano no es su sola forma, sino su composición con la materia. En caso contrario, se estaría definiendo al ser humano mediante un concepto de esencia puramente formal, como es el caso de una definición matemática.

Como mencioné, esta definición metafísica también posee un correlato ético para santo Tomás. Y es que la definición de una acción tiene que ver también con lo que es un acto esencialmente hablando:

"La palabra elección comporta algo que pertenece a la razón o entendimiento y algo que pertenece a la voluntad, pues dice el Filósofo en el Vi Ethic. que la elección es entendimiento apetitivo o apetito intelectivo. Ahora bien, siempre que concurren dos cosas para constituir una sola, una de ellas es como lo formal respecto de la otra. Por eso, Gregorio Niseno dice que la elección no es apetito en si misma ni sólo consejo, sino algo compuesto de ambos. Pues igual que decimos que un animal está compuesto de cuerpo y alma, pero no que es cuerpo en sí mismo ni tampoco que sea sólo alma, sino ambas cosas, lo mismo también la elección. (...) Por consiguiente, el acto por el que la voluntad tiende a algo que se propone como bueno, por estar ordenado al fin por la razón, es materialmente un acto de la voluntad ciertamente, pero formalmente es de la razón" (Aquino, [1265] 2009, pp. 147-148). 
De este modo, podemos decir que la relación entre el intelecto o razón y la voluntad coincide con la relación de lo formal y lo material en toda acción humana. Ya que no hay compuesto humano sin ambos elementos, tampoco puede haber elección sin intelecto ni voluntad. Todo acto libre proviene formalmente del intelecto y materialmente de la voluntad, puesto que lógicamente una persona solamente puede mover su voluntad hacia un fin previamente aprehendido por el intelecto, pero a su vez este acto únicamente se completa por medio de la voluntad. Así, debemos decir que sin el intelecto la voluntad no podría amar el bien, pero sin una voluntad recta nuestro intelecto no podría alcanzar con su visión a dicho bien.

\section{La importancia del amor de caridad para un auténti- co quehacer teológico}

Ahora bien, ¿qué importancia tiene relacionar estas cosas con la esencia de la bienaventuranza y con nuestro quehacer teológico? Decía santo Tomás que sin rectitud de voluntad el intelecto no puede llegar a la contemplación de Dios. De manera que si todo acto es formalmente intelectual y materialmente volitivo, entonces la bienaventuranza también debe componerse de estos elementos de modo esencial. De ello, se deriva que nadie ama lo que no conoce y que la visión de Dios es causa de la bienaventuranza y del amor divino. Sin embargo, en virtud de lo antes dicho, a saber, que la rectitud de la voluntad corresponde a lo material de este acto y la contemplación intelectual a lo formal, también es preciso indicar que no cualquier materia, sino la debidamente dispuesta, es la que es capaz de recibir a la forma. Así, la voluntad debe ser rectificada en algo previamente para que el intelecto pueda buscar su objeto o fin último, en este caso, Dios. ¿Qué es, entonces, una voluntad recta? 
"Pues bien, hemos dicho ya (q. 23 a. 1; q. 25 a. 12) que el amor de caridad tiende hacia Dios como principio de la bienaventuranza, en cuya comunicación se funda la amistad de caridad. Es, por lo mismo, conveniente que entre las cosas amadas por caridad haya algún orden según su relación con el principio primero de ese amor, que es Dios" (Aquino, [1265] 2010, pp. 250-251).

Santo Tomás coloca en el amor de caridad la condición sine qua non para que el amor del ser humano pueda hallarse en orden a Dios. Es decir, que lo que buscamos como rectitud de voluntad no es otra cosa que una voluntad rectificada en el amor de caridad, ya que es el único modo en el que nuestro amor se encuentra realmente ordenado hacia su verdadero fin.

Por estas razones, hay que decir que cuando santo Tomás define la esencia de la bienaventuranza como un acto meramente intelectual, solamente está definiendo como su esencia aquello que la posibilita de un modo formal, pues únicamente está concibiendo como su esencia a aquello que es la forma del acto como tal. Como nadie puede amar lo que no conoce, es lógico pensar que la visión de Dios es la causa del amor que experimentaría la voluntad en la bienaventuranza. Sin embargo, en virtud de las otras palabras de santo Tomás en su obra metafísica y ética, hay que admitir que esta manera de concebir la esencia de la bienaventuranza no puede ser reducida a una cuestión meramente formal, ya que hay otro sentido de esencia como algo compuesto, como lo que constituye o fundamenta una cosa en la realidad. De modo que al apelar a esta concepción metafísica y ética para definir la esencia de la bienaventuranza hay que incluir como parte de su esencia a la rectitud de voluntad en el amor de caridad. De ahí que Orlandis (1942) haya dicho que "la norma de juicio que de continuo aplica el Santo Doctor no suele ser la conducencia o no conducencia al conocimiento de 
Dios, sino la conformidad o disconformidad con el amor de caridad" (p. 8). Así, la esencia de la bienaventuranza tendrá que incluir a la voluntad como su parte material, ya que el intelecto sería solamente su parte formal. Por lo tanto, no puede haber un intelectualismo a secas en la teología de santo Tomás.

¿Qué podemos aprender de esta concepción tomista acerca del último fin de la criatura humana? ¿Cuál es la vigencia de este desarrollo tomista de nuestro entendimiento y voluntad para nuestra teología? Así como la bienaventuranza no se trata de una contemplación disociada ni mucho menos separada de una vida caritativa, tampoco nuestro ejercicio intelectual por más teológico que sea debe estar desligado de una experiencia en el amor de caridad que lo sustente. Sin una vida conducida en el amor de caridad no es posible una contemplación adecuada de Dios ni una comprensión ni enseñanza de lo que representa para nosotros su palabra y su acción. Nuestro quehacer teológico debe contemplar no solamente a Dios como un objeto de intelección o de ortodoxia, sino que debe vivirlo plenamente en el amor de caridad, condición necesaria de su real asimilación. No hay interiorización de la esencia divina en nuestro quehacer teológico si este se reduce a una mera información o pautas que alguien debe cumplir. El mayor conocimiento de Dios no puede desligarse de la búsqueda por vivir cada vez más su amor. Y este amor se ordena en la

200 voluntad por la caridad. En este sentido, podemos decir que sin caridad cualquier tipo de teología o de enseñanza es ociosa, no es cristiana, o incluso es aviesa.

\section{Conclusión}

En general, el espíritu del pensamiento de santo Tomás articula todo tipo de anuncio de la verdad y la vivencia del evan- 
gelio. No basta la búsqueda de la verdad sin una participación en el amor de caridad propio del espíritu evangélico para alcanzar una vida bienaventurada. Santo Tomás no concibe en estas actividades dos realidades separadas o separables, sino que demuestra su relación e inclusive su simultánea necesidad. También propone una teología, cuyo quehacer, lejos de aminorar a la filosofía y a la actividad racional las convierte en indispensables, sin dejar de reconocer la preeminencia de lo afectivo y volitivo en la dimensión humana. Conocimiento y amor, teoría y praxis, razón y fe, filosofía y teología, entre muchas otras complementariedades, se incorporan para constituir unidades fundamentales del pensamiento tomista. Nuestro quehacer teológico debe, pues, implicar un orden, un recto amor a Dios que permita justificar la doctrina que pregonamos y no que, en aras de un fin, muchas veces mal vivido y mal entendido, se justifique cualquier medio. El fin no justifica los medios para santo Tomás, porque es ahí cuando el verbo de Dios no informa ni transforma precisamente por darse una materia indebidamente dispuesta. Es ahí cuando se exacerba la confrontación, cuando impera el dogmaticismo, cuando incluso podemos hasta comportarnos como cómplices de gobiernos autoritarios o incurrimos en un mero ecumenismo de palestra. Nuestro quehacer teológico debe estar inspirado en una vida ordenada hacia Dios. Nuestro quehacer teológico, según santo Tomás de Aquino, debe sustentarse y plasmarse a la luz de aquellas palabras de Cristo en Mateo 5, 8 que dicen: "Bienaventurados los puros de corazón, porque ellos verán a Dios”.

\section{Recibido: 10 de febrero del 2019}

Aprobado: 15 de junio del 2019 


\section{Referencias bibliográficas}

Aquino, Santo Tomás

(2009) Suma de teología. Biblioteca de Autores Cristianos, Edición dirigida por los Regentes de Estudios de las Provincias Dominicanas en España. Presentación por Damian Byrne, O. P. Maestro general de la orden de predicadores.

Aquino, Santo Tomás

(2010) Suma de teología. Biblioteca de Autores Cristianos, Edición dirigida por los Regentes de Estudios de las Provincias Dominicanas en España. Presentación por Damian Byrne, O. P. Maestro general de la orden de predicadores.

Aquino, Santo Tomás

(2011) El ente y la esencia. Traducción, estudio preliminar y notas de Eudaldo Forment. Pamplona: EUNSA S. A.

Copleston, F.

(2000) Historia de la filosofía (vol. II: De San Agustín a Escoto ol. III: De Ochkam a Suárez). Barcelona: Ed. Ariel, S. A.

Copleston, F.

(2004) Historia de la filosofía (vol. III: De Ochkam a Suárez). Barcelona: Ed. Ariel, S. A.

Gilson, E.

202 (1985) La filosofía en la Edad Media (2a. ed.). Versión espanóla de Arsenio Pacios y Salvador Caballero. Barcelona: Ed. Gredos.

Gilson, E.

(2002) El tomismo, introducción a la filosofía de Santo Tomás de Aquino. Pamplona: EUNSA. 
Gilson, E.

(2007) Juan Duns Escoto, introducción a sus posiciones fundamentales. Pamplona: EUNSA.

Orlandis, R.

(1942) El último fin del hombre según Santo Tomás. Barcelona: Manresa.

Wulf, M.

(1945) Historia de la filosofía medieval. Traducción de Jesús Toral Moreno. México, D. F., Ed. Jus. 